\title{
Motor DC PID System Regulator for Mini Conveyor Drive Based-on Matlab
}

\author{
Abdul Latif ${ }^{1}$, Afif Zuhri Arfianto ${ }^{2}$, Hendro Agus Widodo ${ }^{3}$, Robbi Rahim ${ }^{4}$, Elsayed T. Helmy ${ }^{5}$ \\ ${ }^{1}$ Universitas Islam Sultan Agung, Semarang, Indonesia \\ ${ }^{2,3}$ Politeknik Perkapalan Negeri Surabaya, Surabaya, Indonesia \\ ${ }^{4}$ School of Computer and Communication Engineering, University of Malaysia Perlis, Malaysia \\ ${ }^{5}$ National Institute of oceanography and fisheries, Alexandria \\ Email: 4bdullatif.u.m.y@gmail.com, afifzuhri@ieee.org, hendro.aw@ppns.ac.id, \\ robbirahim@ieee.org, stalaat41@gmail.com
}

\begin{abstract}
The goal of the research was to develop a Proportional Integral Derivative (PID) control DC motor system as a Matlab-based driver mini conveyor to discover how to regulate speed on an actual mini conveyor where certain factors that impact the research are not considered 0 . The hardware configuration of the mini conveyor used hollow steel as a frame and two copies of the roller belt for the stretch belt conveyor. The PID control system used an empirical approach to get the DC motor's response system to determine the best fit of proportional gain, integral gain and derivative gain, and then implement those PID control systems using Matlab and Arduino as the tools for data acquisition. The speed sensor (Rotary Encoder) was mounted on the roller belt to accurately gain read speed. This sensor will submit data on every increasing in PWM to accurately measure the speed and control speed at the same time, based on the set points. The consequence of this work was the proportional gain values $=\mathbf{0 . 9 4 6 2 4 7 4 7}$, the Integral gain $=$ 51.4023958 and the derivative gain $=0.01941504$. The PID control, designed to monitor the response of motor DC speed on this research, had successfully reached set point value and decreased steady state error from 47.16 percent to 1.015188 percent (unloaded) and 2.2020751 percent (loaded) on the real response device.
\end{abstract}

Keywords - Arduino, PID Controller, Mini Conveyor, Angular speed control, Proportional Integral Derivative

\section{INTRODUCTION}

A conveyor is a mechanical system capable of moving goods from one place to another. It has been widely used in the industry for large and sustainable goods transportation. In the production process, the products have a very diverse weight. If overloaded, it can impact the speed of the motor / conveyor on a conveyor not fitted with speed control.

When the conveyor is loaded, the anchor current will increase as the load increases. The increase in the current will cause the interference of the anchor field in the main field to enlarge so that the neutral point is increasingly shifted. Shifting the main field will increase the losses on the brush if the position of the brush is not adjusted. The average efficiency value on a motor without speed control in a study conducted by Stephanus Antonius Ananda is relatively low, around $70 \%$. The research has conducted a motor speed control system using a PID controller. In the study, they use a line follower robot as a plant and produces a maximum overshoot that is quite large, reaching $10 \%$. It will affect the speed of production. It will affect the speed of production. The advances in science and technology generate many ways to control motor speed, one of which uses a PID controller.

Some previous studies have conducted speed control research using DC motors. These researchers, Mohammad and Billah, conducted a research analysis of speed control of DC series motors using a diverter and observing saturation points of speed. The speed of the dc series motor can be controlled using a diverter in the motor field circuit [1]. The linear quadratic regulator and the predictive control model used for optimal control of the DC motor speed were studied by Sahoo. In the DC motor model, different control techniques are used to control the speed angle [2].

The dynamic SMC control scheme with a PID controller that is adapted to the adaptive speed control of a DC motor is examined by Dil Kumar. Adaptive PID with dynamic shear mode control techniques is proposed to control the speed of the excited DC motor separately [3]. Das conducted research on the optimal tuning of the PID controller using the GWO algorithm for speed control on the DC motor. Bio-inspired meta-heuristic soft computation methods to optimize the performance of the PID controller used in DC motor speed control [4]. The speed control of DC motors that are driven separately is supported by photovoltaic energy researched by Jeddi. Speed control of the direct current motor (SEDM) separately using the Maximum Power Point Tracking (MPPT) strategy applied to the DC-DC Boost converter [5].

The linearization approach for anti-windup synthesis and implementation for DC motor speed control was investigated by Saqib. Anti-windup gain is designed for non-linear systems that have input saturation [6]. Nath conducted research on energy-efficient DC drive speed control based on Neural Networks. DC motors have excellent speed control characteristics and are widely used in various industrial applications [7].

The design and simulation of a DC PWM motor speed regulator based on Proteus was investigated by Sun. The Proteus software is used to design and simulate PWM speed regulators of DC motors and get the main control of the motor [8]. Microprocessor-based closed loop speed control on DC motors using PWM was investigated by Ravi Kumar. Most 
Electric drive systems must have these benchmark properties such as linear control, reliability and stable operation [9]. Remote DC motor control using Embedded Linux and FPGA was investigated by Jaziri. Codeign architecture in which the embedded Linux operating system running on Beaglebone communicates with FPGA via the SPI protocol with a master slave scheme [10].

The speed control of ANFIS based DC motors was investigated by Chaudhary. Comparative analysis of different controller configurations for DC motor speed control [11]. The comparison of P-I and I-P controllers using the ZieglerNichols tuning method for speed control of DC motors was investigated by Bhatti. Ziegler-Nichols tuning method for tuning of a Proportional-Integral (P-I) and IntegralProportional (I-P) controller for a DC motor to control its speed [12]. The control of the speed of a DC motor using voice commands was investigated by Sai. There are many techniques for speed control such as using sound as an input control will reduce manual operation [13].

Simulink simulation of a brushless DC motor speed control system was examined by According to the brushless mathematical model researched by Ling Xu. DC motors, using MATLAB / Simulink to build a variety of independent functional modules, and are integrated into a simulation model of a DC motor control system [14]. The control speed of a four-quadrant closed DC motor is examined by Patil. Low Cost, high performance control Chopper Based Four closed loop of DC Motor [15].

PWM speed control of DC motors based on singular perturbation techniques was investigated by Yurkevich. The proportional-integral (PI) controller is designed to control the motor current and speed based on a single perturbation technique so that the scale-time movement is artificially induced in a closed loop system [16]. Improvement of the performance of the uncensored DC motor control using fuzzy logic was examined by Nguyen Thanh. Despite the development of various types of electric motors, DC motors are still used in many industrial applications because this type of motor can be easily controlled and has a wide range to adjust [17].

The design and performance evaluation of a strong SMC scheme for DC motor speed control was investigated by Dil Kumar T R. The design and performance evaluation of a strong SMC scheme for DC motor speed control [18]. The stabilization of the rotation speed of a DC motor with PWM in the control channel based on the time scale separation method was investigated by Stepanov. The proportionalintegral (PI) controller is designed to control the motor current and speed based on a single perturbation technique so that the scale-time movement is artificially induced in a closed loop system [19]. Speed control for DC motors with pulse width modulation (PWM) method using an infrared remote control based on the ATmega16 microcontroller was investigated by Agung. Direct current (DC) motor speed control for various applications is very important [20].

Al-Maliki conducted research on tuning an FLC-based PID controller for uncensored speed control of a DC motor. Sensor less speed control of permanent magnet DC motors using voltage and current sensors is not ideal [21]. The design and comparative study of the maximum photovoltaic power point tracker with DC motor speed control was investigated by Sultan. Finding the biggest power point by the solar panel direct current motor separately controls the excited speed [22]. The design of a real-time PID tracking controller using the Arduino Mega 2560 for permanent magnet DC motors under real interference was investigated by Adel. The popularity of PID controllers can be attributed in part because of their strong performance in various operating conditions and partly because of its functional simplicity [23]. The GWO / PID approach for Optimal Control of DC Motors was investigated by Ahmed. This work is related to the application of Gray Wolf Optimization (GWO) for optimal control of DC motor speed [24]. Controlling the AVR Voltage and Speed of a DC Motor using a Modified PI-PD Controller was investigated by Singh. Methods of adjusting the PI-PD controller, which are validated using simulation results [25].

The application of DC Motor Speed Control Logic to FPGA was investigated by Bhate. A system that can automate the speed control process and enables the speed control of DC motors that are designed more accurately [26]. Sliding Mode Controller (SMC) Adjusts the Speed Control of a DC Motor researched by Rakhonde. The sliding mode controller is one of the best tools for analyzing second-order dynamic systems [27]. Agarwal conducted research on the comparative analysis of PID controllers for DC motor speed control with the Intelligent Optimization algorithm. Comparative analysis between optimization gray wolf (GWO) and Sine Cosine (SCA) algorithm has been done to adjust the PID controller for DC motor speed control [28]. Wahyudi conducted research on the design of the self-tuning regulator for speed control of brushless DC motors. Brushless DC motor (BLDC) is one type of dc electric motor that has various advantages such as higher efficiency, torque under the low speed range, and power density, and lower maintenance because this motor does not use brushes in the turn process [29]. The PV is fed to a Separate Relaxing DC Motor with Closed Loop Speed Control researched by Narendra. The closed loop control of a single quadrant based chopper is driven separately by an excited DC motor [30].

The study discusses the DC Motor PID Regulatory System as a Mini Conveyor-Based Matlab Drive to find out how to regulate the motor speed at the actual mini conveyor plant, where certain factors are not considered 0 . The PID regulation system is applied as a speed control module in the system that uses Matlab and Arduino as data acquisition tools to read speed sensors and control motor speed to suit the desired set point.

\section{METHOD}

This work aimed to use and establish mathematical models, theories, or physical hypotheses. It had employed a quantitative approach. The measurement phase in this approach is central to quantitative study, since it offers a fundamental relationship between empirical observation and quantitative mathematical language.

In this research, Arduino E and Matlab software worked for simulating the running system, used along with the plant design that produced a speed response to the load on the mini conveyor plant. The research referred to previous journals included in the literature review. The system design was formulated based on the existing industrial phenomena, and the PID configuration used analytical methods. 


\section{A. Hardware design}

Figure 1 illustrates the overall hardware circuit scheme for the motor speed regulation system in the PID-based mini conveyor design.

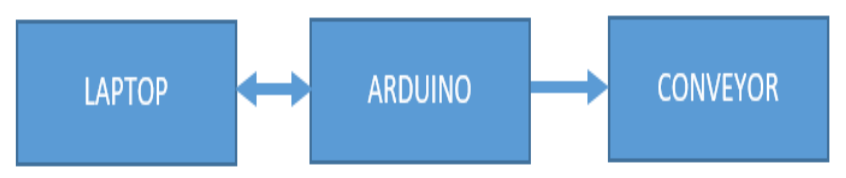

Fig. 1. System hardware scheme

The Figure 1 shows that the computer, as the data processing unit, receiver and software sender, displays a Matlab GUI (Graphical User Interface) for reading data in graphical form through a USB cable to Arduino UNO R3. The Matlab software used was the Matlab 2009a model which was combined with Arduino to construct a motor speed control system on the mini conveyor based on PID. The monitoring display was derived from the Matlab in the form of graphs / numerical values obtained from the sensor reading.

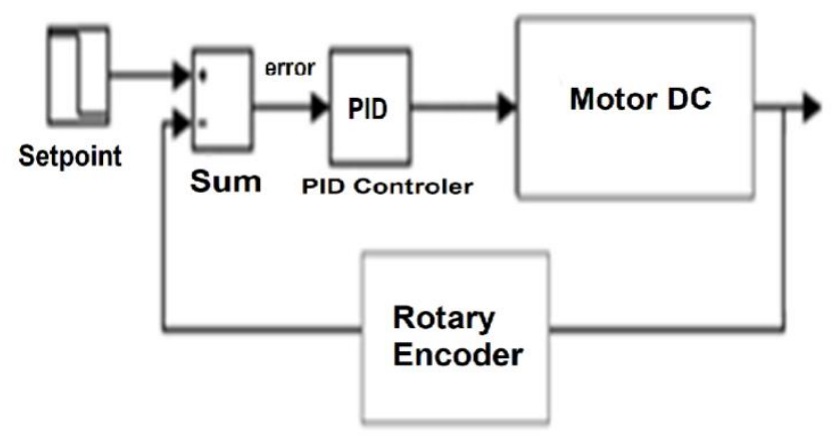

Fig. 2. PID system block diagram

Figure 2 is a block diagram of a motor speed regulation system in the design of a mini conveyor. It shows that the input reference value (set point) of the system is the desired speed. The result of the PID control output is the movement of the motor that gets pulses from PWM to regulate the incoming power to the motor. The speed sensor (Rotary Encoder) will be used to measure the speed of the mini conveyor belt in $\mathrm{m} / \mathrm{s}$ (meters per second), and the result of the reading value is as the feedback value.

\section{B. Firmware design}

The software design applied in the research was a program incorporated into the Arduino microcontroller. The programming was made using a special programming language by Arduino in Arduino IDE v1.6.12.

The program started by setting up the desired set-point value, and then the motor would run. The rotary encoder attached to the motor provided RPM to the PID controller, calculated using an analytical method to provide feedback so that the motor speed could be adjusted. When the set-point did not match, the process would be repeated until reaching the desired set-point. Figure 3 displays the system workflow.

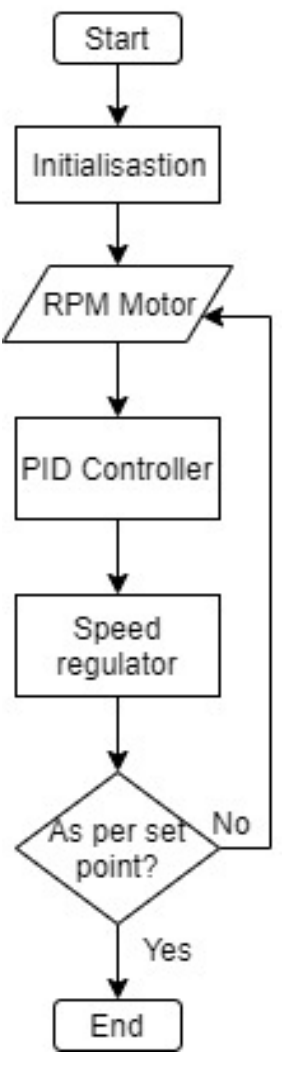

Fig. 3. System work flow

\section{IMPLEMENTATION}

The research testing and analysis included analysis and testing of the plant control system design for PID, application of the PID control configuration at the plant, and results of the PID control test.

\section{A. System circuit and interface}

The circuit design tests included power supply, rotary encoder sensor, microcontroller, and motor driver. Figure 4 displays the circuit test blocks.

The power supply has an important role as a source of voltage in the system. The designed system used two power supplies. The first power supply had a $5 \mathrm{~V}$ DC output to provide voltage to the microcontroller block and sensor, and the second had a $12 \mathrm{~V}$ DC output to provide voltage to the motor driver.

The rotary encoder sensor calibration process was carried out to get the RPM value on the DC motor used. The calibration aid used was the DT-2234C digital tachometer. Table 1 presents the calibration.

TABLE I. ROTARY ENCODER SENSOR CALIBRATION RESULT

\begin{tabular}{|c|c|c|c|}
\hline No. & $\begin{array}{c}\text { Sensor Rotary } \\
\text { Encoder } \\
\text { Reading in RPM }\end{array}$ & $\begin{array}{c}\text { Tachometer } \\
\text { Digital Reading } \\
\text { in RPM }\end{array}$ & $\begin{array}{c}\text { Supplying } \\
\text { Power (V) }\end{array}$ \\
\hline 1. & 47.55 & 49 & 12 \\
\hline 2. & 57.07 & 54.30 & 12 \\
\hline 3. & 91.50 & 89.40 & 12 \\
\hline
\end{tabular}


A microcontroller testing was done by connecting the sensor to the microcontroller to calculate motor speed. The results were then displayed on a PC through Arduino software. The microcontroller used was Arduino Uno R3. The data from the microcontroller block was the same as those presented in table 1 because the microcontroller contained the processing data inputted by the rotary encoder sensor.

The motor driver block testing was performed by giving 0 percent, 25 percent, 50 percent, and 75 percent variations in the PWM duty cycle to the motor driver and measuring the DC motor speed without being attached to the conveyor. Figure 4 shows the driver test for the DC motor.

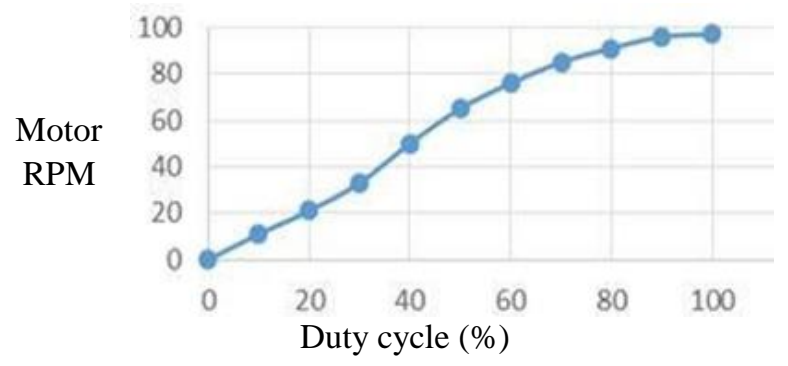

Fig. 4. Motor DC driver test

\section{B. PID control configuration}

The method used to find system modeling was the method approach to order-1 system characteristics with the required parameters $\mathrm{K}$ and $\tau$. It was done by obtaining a system response that would be used to obtain a model or transfer function of a system. The transfer function would be employed as a comparison between real and simulated responses. In this research, the modeling was performed with a $90 \mathrm{rpm}$ set-point at $12 \mathrm{~V}$ voltage as shown in Figure 5.

$$
\begin{gathered}
G_{(s)}=\frac{K}{\tau_{s}+1} \\
G_{(s)}=\frac{0.528403}{0.0184086258 s+1}
\end{gathered}
$$

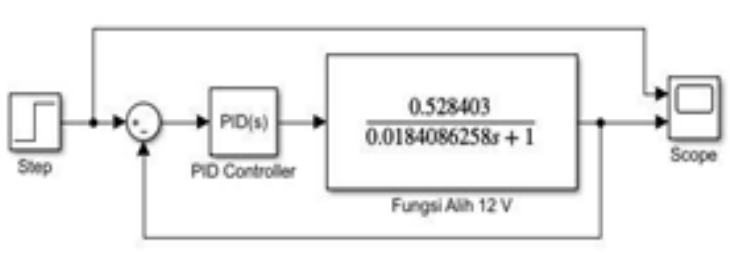

Fig. 5. Simulink block diagram of the PID system

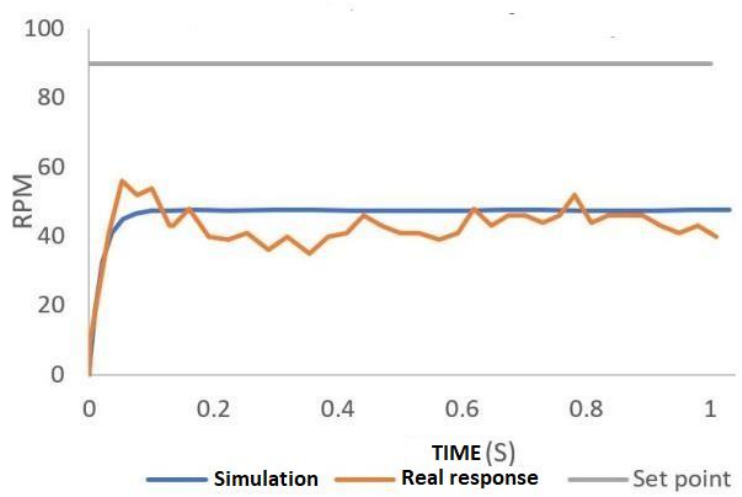

Fig. 6 Comparison graph between simulation response and real response

Figure 6 illustrates the comparison graph between simulation and real responses. Based on the response graph, the real response parameters could be calculated openly in the forms of $t s$ (Settling Time), tr (Rising Time), $t d$ (Delay Time), and SSE (Steady State Error) with values of $\tau=$ 0.0184086258 seconds.

Table 2 presents the calculation of PID controller parameters with the settling time performed two times longer.

TABLE II. PID PARAMETERS

\begin{tabular}{|c|c|}
\hline Parameter & Value \\
\hline Proportional gain $K_{p}$ & 0.94624747 \\
\hline Integral gain $K_{i}$ & 51.4023958 \\
\hline Derivative gain $K_{d}$ & 0.01941504 \\
\hline
\end{tabular}

By entering the values of $K_{p}, K_{i}$, and $K_{d}$ on the mini conveyor plant, the real response graph of the transfer function set-point was 90 at a voltage of $12 \mathrm{~V}$, as shown in Figure 7.

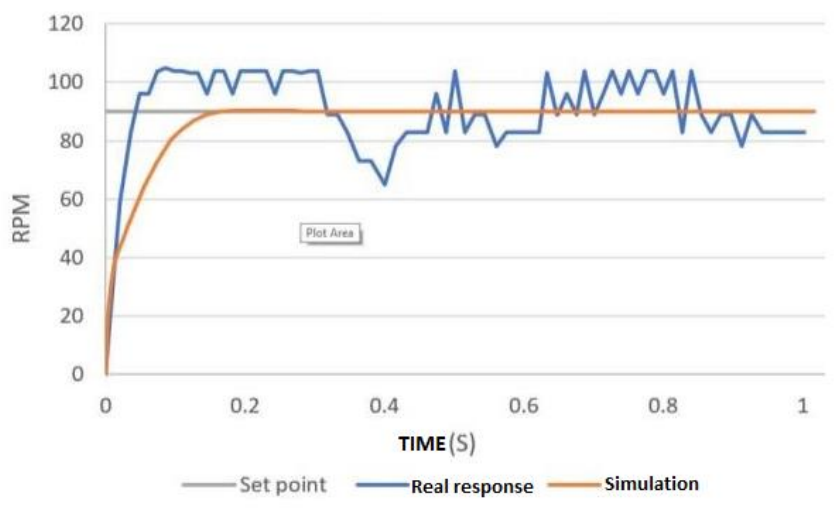

Fig. 7. Comparison graph between simulation response and real response at transfer function as $12 \mathrm{~V}$

Figure 7 shows the system response to the $12 \mathrm{~V}$ switching function test with PID Calculation of system response parameters with $\tau=0.02058345$ seconds, as presented in tabular form in Table 3.

TABLE III. REAL SYSTEM RESPONSE PARAMETERS

\begin{tabular}{|l|c|c|}
\hline \multicolumn{1}{|c|}{ Parameter } & Without PID & With PID \\
& $(\mathbf{s})$ & $(\mathbf{s})$ \\
\hline Settling time $(t s)$ & 0.055225 & 0.061750 \\
\hline Rise Time $(t r)(10-90 \%)$ & 0.040447 & 0.045226 \\
\hline Delay Time $(t d)$ & 0.012759 & 0.014267 \\
\hline Steady State Error $(\mathrm{SSE})$ & $47.16 \%$ & $1.02 \%$ \\
\hline
\end{tabular}

\section{PID control results}

The next stage was implementing these parameters into the PID controller. The test was carried out three times with a load of $1 \mathrm{~kg}, 2 \mathrm{~kg}$, and $3 \mathrm{~kg}$. The result is shown in Table 4 . 
TABLE IV. SYSTEM RESPONSE TEST PARAMETERS

\begin{tabular}{|l|c|c|c|}
\hline \multicolumn{1}{|c|}{ Parameter } & Load 1Kg & Load 2Kg & Load 3Kg \\
\hline Steady time (5\%) & 0.035399 & 0.038671 & 0.035109 \\
\hline Rise time (10-90\%) & 0.025927 & 0.028323 & 0.025714 \\
\hline Delay time & 0.008179 & 0.008935 & 0.008112 \\
\hline Steady State Error & $1.133211 \%$ & $2.20207 \%$ & $0,60197 \%$ \\
\hline
\end{tabular}

\section{CONCLUSION}

Based on research and testing conducted, it is concluded that regulating motor speed can use analytical methods, where the motor's real response and the values of Proportional gain $K_{p}$, integral gain $K_{i}$, and derivative gain $K_{d}$ can be calculated. The study finds that the value of $K_{p}$ is $0.94624747, K_{i}$ is 51.4023958 , and $K_{d}$ is 0.01941504 .

The microcontroller used to apply PID in this study is Arduino Uno R3, connected to the Rotary Encoder sensor to regulate the speed of the conveyor. Referring to Table 4 of the PID controller, designed to control the DC motor speed response, it shows that it succeeds in reaching the setpoint value and reducing the ESS (Error Steady State) on the real system response from $47.16 \%$ to $1.02 \%$ (no load) and $2.2020751 \%$ (with $2 \mathrm{~kg}$ load).

\section{REFERENCES}

[1] A. Mohammad and S. M. B. Billah, "Analysis of speed control of series DC motor using diverter and observation of speed saturation point," in 2015 International Conference on Electrical Engineering and Information Communication Technology (ICEEICT), 2015, no. May, pp. 1-4.

[2] S. Sahoo, B. Subudhi, and G. Panda, "Optimal speed control of DC motor using linear quadratic regulator and model predictive control," in 2015 International Conference on Energy, Power and Environment: Towards Sustainable Growth (ICEPE), 2015, pp. 1-5.

[3] T. R. Dil Kumar and S. J. Mija, "Dynamic SMC control scheme with adaptively tuned PID controller for speed control of DC motor," in 2015 IEEE International Conference on Industrial Technology (ICIT), 2015, vol. 2015-June, no. June, pp. 187-191.

[4] K. R. Das, D. Das, and J. Das, "Optimal tuning of PID controller using GWO algorithm for speed control in DC motor," in 2015 International Conference on Soft Computing Techniques and Implementations (ICSCTI), 2015, pp. 108-112.

[5] N. Jeddi, N. Ouasli, L. El Amroui Ouni, and F. Tadeo, "Speed control of a separately-excited DC motor powered by photovoltaic energy," in IREC2015 The Sixth International Renewable Energy Congress, 2015, pp. $1-6$.

[6] N. U. Saqib, M. Rehan, and N. Iqbal, "Linearization approach for antiwindup synthesis and implementation for DC motor speed control," in 2015 Symposium on Recent Advances in Electrical Engineering (RAEE), 2015, pp. 1-4.

[7] K. Nath, A. Kumar, A. Roy, and A. Sharma, "Speed Control of Neural Network Based Energy Efficient DC Drive," in 2015 Second International Conference on Advances in Computing and Communication Engineering, 2015, pp. 318-323.

[8] J. Sun and Q. Sun, "Design and simulation of PWM DC motor speed regulator based on Proteus," in 2015 International Conference on Fluid Power and Mechatronics (FPM), 2015, pp. 1210-1213.

[9] K. . Ravi Kumar, Jaideep, Rohit, and Vikas, "Microprocessor based closed loop speed control of DC motor using PWM," in 2015 International Conference on Control, Instrumentation, Communication and Computational Technologies (ICCICCT), 2015, vol. 2, pp. 255257.

[10] I. Jaziri, L. Chaarabi, and K. Jelassi, "A remote DC motor control using Embedded Linux and FPGA," in 2015 7th International Conference on Modelling, Identification and Control (ICMIC), 2015, no. Icmic, pp. $1-5$.

[11] H. Chaudhary, S. Khatoon, and R. Singh, "ANFIS based speed control of DC motor," in 2016 Second International Innovative Applications of Computational Intelligence on Power, Energy and Controls with their Impact on Humanity (CIPECH), 2016, pp. 63-67.

[12] S. A. Bhatti, S. A. Malik, and A. Daraz, "Comparison of P-I and I-P controller by using Ziegler-Nichols tuning method for speed control of DC motor," in 2016 International Conference on Intelligent Systems Engineering (ICISE), 2016, pp. 330-334.

[13] T. M. Sai and S. K. Kumar, "Speed control of DC motor using voice commands," in 2016 International Conference on Computation of Power, Energy Information and Commuincation (ICCPEIC), 2016, pp. $800-803$.

[14] Ling Xu, Jian-Guo Song, and Qiang-Qiang Lin, "Brushless DC motor speed control system Simulink simulation," in 2016 IEEE International Conference on Power and Renewable Energy (ICPRE), 2016, pp. $62-$ 66.

[15] V. S. Patil, S. Angadi, and A. B. Raju, "Four quadrant close loop speed control of DC motor," in 2016 International Conference on Circuits, Controls, Communications and Computing (I4C), 2016, pp. 1-6.

[16] V. D. Yurkevich and N. A. Stepanov, "PWM speed control of DC motor based on singular perturbation technique," in 2014 6th International Congress on Ultra Modern Telecommunications and Control Systems and Workshops (ICUMT), 2014, vol. 2015-Janua, no. January, pp. 434-440.

[17] S. Nguyen Thanh, C. Nguyen The, and H. Ha Xuan, "Improved performance of a sensorless DC motor control using fuzzy logic," in 2014 5th International Conference on Intelligent and Advanced Systems (ICIAS), 2014, pp. 1-6.

[18] Dil Kumar T R and Mija S.J, "Design and performance evaluation of robust SMC schemes for speed control of DC motor," in 2014 IEEE International Conference on Advanced Communications, Control and Computing Technologies, 2014, pp. 88-92.

[19] N. A. Stepanov, "Stabilization of rotational speed of the DC motor with PWM in control channel based on time-scale-separation method," in 2014 12th International Conference on Actual Problems of Electronics Instrument Engineering (APEIE), 2014, pp. 1-1.

[20] I. G. A. P. R. Agung, S. Huda, and I. W. A. Wijaya, "Speed control for DC motor with pulse width modulation (PWM) method using infrared remote control based on ATmega16 microcontroller," in 2014 International Conference on Smart Green Technology in Electrical and Information Systems (ICSGTEIS), 2014, no. November, pp. 108-112.

[21] A. Y. Al-Maliki and K. Iqbal, "FLC-based PID controller tuning for sensorless speed control of DC motor," in 2018 IEEE International Conference on Industrial Technology (ICIT), 2018, vol. 2018-Febru, pp. 169-174.

[22] N. S. Sultan, "Design and comparative study of photovoltaic maximum power point tracking converter with DC motor speed control," in 2018 1st International Scientific Conference of Engineering Sciences - 3rd Scientific Conference of Engineering Science (ISCES), 2018, vol. 2018-Janua, pp. 74-79.

[23] Z. Adel, A. A. Hamou, and S. Abdellatif, "Design of Real-time PID tracking controller using Arduino Mega 2560for a permanent magnet DC motor under real disturbances.," in 2018 International Conference on Electrical Sciences and Technologies in Maghreb (CISTEM), 2018, pp. 1-5.

[24] A. Ahmed, R. Gupta, and G. Parmar, "GWO/PID Approach for Optimal Control of DC Motor," in 2018 5th International Conference on Signal Processing and Integrated Networks (SPIN), 2018, pp. 181186.

[25] V. K. Singh, S. Sharma, and P. K. Padhy, "Controlling of AVR Voltage and Speed of DC Motor using Modified PI-PD Controller," in 2018 2nd IEEE International Conference on Power Electronics, Intelligent Control and Energy Systems (ICPEICES), 2018, vol. 2, no. 1, pp. 858863.

[26] D. Bhate, S. Tantry, J. Gopinath, and K. A. Naveen, "Implementation of DC Motor Speed Control Logic on FPGA," in 2018 3rd International Conference for Convergence in Technology (I2CT), 2018, pp. 1-4. 
[27] S. Rakhonde and V. Kulkarni, "Sliding Mode Controller (SMC) Governed Speed Control of DC Motor," in 2018 3rd IEEE International Conference on Recent Trends in Electronics, Information \& Communication Technology (RTEICT), 2018, pp. 1657-1662.

[28] J. Agarwal, G. Parmar, and R. Gupta, "Comparative Analysisof PID Controller for Speed Control of DC motor with Intelligent Optimization Algorithms," in 2018 International Conference on Advances in Computing, Communication Control and Networking (ICACCCN), 2018, pp. 273-277.
[29] Wahyudi, M. Rosaliana, B. Setiyono, and Sumardi, "Design of SelfTuning Regulator for Brushless DC Motor Speed Control," in 2018 International Conference on Smart Green Technology in Electrical and Information Systems (ICSGTEIS), 2018, vol. 7, pp. 1-4.

[30] A. Narendra, N. Venkataramana Naik, and N. Tiwary, "PV fed Separately Excited DC Motor with a Closed Loop Speed Control," in 2018 IEEE 8th Power India International Conference (PIICON), 2018, pp. $1-4$. 